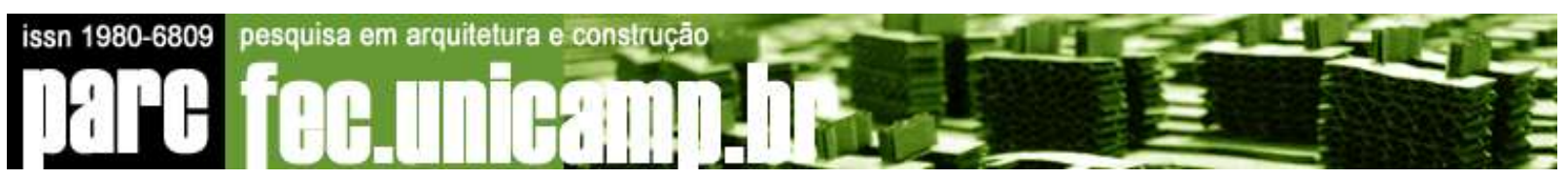

\title{
Tratamento de esgoto de uma unidade de ensino superior por meio de um sistema de zona de raízes
}

Sewage treatment unit using a system of root zone

DOUGLAS P. S. PITALUGA

RICARDO P. A. REIS

ROGÉRIO DE A. ALMEIDA

SAULO B. S. SOUZA

BÁRBARA C. C. DE M. ROCHA

Graduação em Construção Civil/Edifícios pelo Instituto Federal de Goiás - IFG. Mestre em Engenharia do Meio Ambiente da Escola de Engenharia Civil da Universidade Federal de Goiás - UFG. Professor permanente do Instituto Federal de Goiás - IFG.

Engenheiro Civil pela Universidade Federal de Goiás (UFG). Mestre em Engenharia Civil pela Universidade Federal de Goiás. Doutorando do Curso de Pós-Graduação em Engenharia Civil da FEC - UNICAMP. Professor dos cursos de graduação em engenharia civil e engenharia ambiental da UFG.

Graduação, mestrado e doutorado em Agronomia pela Universidade Federal de Goiás - UFG. Professor adjunto da Universidade Federal de Goiás, para os cursos de Agronomia, Zootecnia e mestrado em Engenharia de Meio Ambiente.

Engenheiro Civil pela UNICAMP. Mestre em Engenharia Civil pela UNICAMP. Doutorando em Ciências Ambientais pela Universidade Federal de Goiás (UFG). Professor dos cursos de graduação em engenharia civil e engenharia ambiental da UFG.

Arquiteta e Urbanista pela Universidade Católica de Goiás. Fiscal de Edificações e Loteamentos da Prefeitura Municipal de Goiânia e Professora do Instituto Federal de Goiás. Mestre em Engenharia do Meio Ambiente pela Universidade Federal de Goiás.

douglas.pitaluga@gmail.com

rpareis@gmail.com

raa@agro.ufg.br

saulobruno@hotmail.com

barbaracristinarocha@gmail.com 


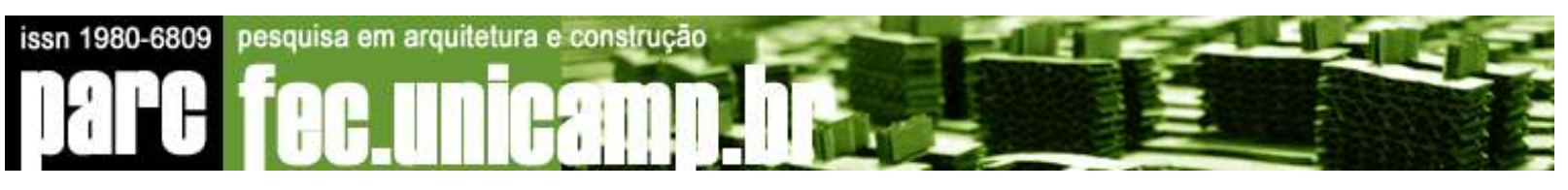

\section{Resumo}

O uso de plantas no tratamento de águas residuais é uma alternativa eficiente, sustentável e de baixo custo em comparação ao tratamento convencional. Este estudo teve como objetivo avaliar a eficiência do sistema de zona de raiz em um tratamento de esgoto sanitário, para as condições climáticas de Goiânia-GO, Brasil. Para isso, foi construída uma estação de tratamento experimental na Escola de Engenharia Civil, da Universidade Federal de Goiás (EEC / UFG), consistindo de uma fossa séptica, filtro anaeróbio e três camaras biológica de zona de raiz, em paralelo, usando areia e brita zero e brita número um, respectivamente, como substrato. O sistema foi eficiente na remoção de DBO $(98,5 \%)$, DQO $(95,8 \%)$ e coliformes termotolerantes $(99,99 \%)$.

Palavras-chave: Fitorremediação; wetlands; alagados construídos; águas residuárias; tratamento de esgoto.

\section{Abstract}

The use of plants in wastewater treatment has been ratified as an alternative efficient, sustainable and of low cost for conventional treatment. This study aimed to evaluate the efficiency of root zone system at a sanitary sewage treatment, for the climatic conditions of Goiânia-GO, Brazil. For this, it was built an experimental treatment station at the School of Civil Engineering, from the Federal University of Goiás (EEC / UFG), consisting of a septic tank, an anaerobic biological filter and three root zone beds, in parallel, using sand and crushed stones number zero and number one, respectively, as a substrate. The system was efficient in the removal of BOD (98.5\%), COD (95.8\%) and thermotolerant coliforms (99.99\%).

Keywords: Phytoremediation; wetlands; wastewater; sewage treatment. 


\section{Tratamento de esgoto de uma unidade de ensino superior por meio de um sistema de zona de raízes}

\section{Introdução}

O destino final do esgoto sanitário é, geralmente, o encaminhamento a um corpo de água. O lançamento de esgotos sem tratamento adequado vem acelerando dia após dia a degradação das águas superficiais. O avanço deste processo pode provocar grandes alterações nos ecossistemas aquáticos, como mortandade de peixes, florescimento de algas tóxicas, perda da biodiversidade, predominância de algumas espécies e desaparecimento de outras, causando possíveis modificações nas cadeias alimentares, além dos impactos sociais, econômicos e de saúde pública, pela perda de água em qualidade e quantidade (PARESCHI, 2004).

A quantidade de esgotos produzidos pela humanidade passou a ser superior à capacidade da natureza em depurá-los. Portanto, faz-se necessário tratar o esgoto gerado, antes de lançá-lo no corpo receptor. Os efluentes das ETE's (Estação de Tratamento de Esgoto) devem, simultaneamente, atender às condições e padrões de lançamento de esgotos e não ocasionar a ultrapassagem das condições e padrões de qualidade de água, estabelecidos para as respectivas classes, nas condições da vazão de referência (CONAMA, 2005).

Diversas pesquisas têm buscado formas alternativas de tratamento de efluentes, principalmente o urbano, que representa um grande aporte de materiais orgânicos, que são lançados diariamente nos cursos de água. Segundo Heller e Nascimento (2005), estes estudos devem considerar, necessariamente, a realidade sócio-econômico-cultural do país, realidade sobre a qual os potenciais benefícios das ações e da pesquisa se aplicarão. Assim, devem ser considerados o grau de desenvolvimento econômico do país, seus desequilíbrios ambientais e sociais, sua realidade sanitária e a cultura de seu povo.

A utilização de espécies vegetais no tratamento de esgoto representa uma tecnologia emergente que está se revelando como uma alternativa, eficiente e de baixo custo, aos sistemas convencionais (PARKINSON et al., 2004). Esses sistemas podem ser implantados no local onde o esgoto é gerado, são facilmente operados, requerem baixo consumo de energia e são mais flexíveis e menos susceptíveis a variações nas taxas de aplicação de esgoto (BRIX, 1993; SOLANO et al., 2004). Integram-se ao ambiente e são caracterizados como tecnologia apropriada e auto-sustentável (PRESZNHUK et al., 2003). Sua principal 


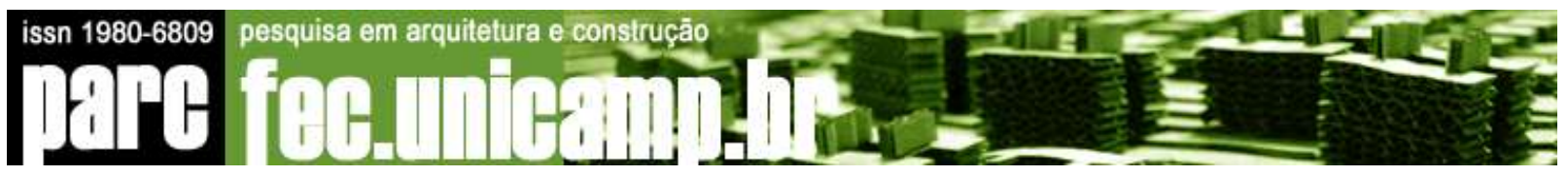

desvantagem está na maior necessidade de área para a implantação do sistema de tratamento (BRIX, 1993), o que nem sempre é um fator limitante, especialmente no Brasil, país de condições climáticas favoráveis para o desenvolvimento e manutenção das plantas utilizadas nas unidades de tratamento. Este fator contribui consideravelmente para a redução das áreas necessárias para a instalação da estação de tratamento, principalmente se houver unidades de pré-tratamento do esgoto, tais como: tanques sépticos e/ou reatores biológicos aeróbicos ou anaeróbicos (PHILIPPI e SEZERINO, 2004).

Segundo Valentim (2003), apesar da existência de várias pesquisas sobre tratamento de esgotos com plantas no Brasil, ainda são poucos os sistemas avaliados continuamente e por um longo período de tempo, e nem sempre os parâmetros de análise e a metodologia de condução adotada pelos pesquisadores coincidem, gerando, às vezes, dificuldades de comparação entre os diversos trabalhos.

A utilização de plantas no tratamento de esgotos já vem sendo aplicada, de forma experimental, em algumas edificações no estado de Goiás. Os sistemas implantados têm se mostrado bastante eficientes no processo de purificação de águas residuárias (ALMEIDA, 2005; ALMEIDA et al., 2007). Apesar dos sistemas de tratamento de esgoto por plantas se mostrarem promissores, ainda existe a necessidade de desenvolvimento de novas pesquisas com vistas a obter novos conhecimentos e subsídios para o seu dimensionamento e uso na região.

\subsection{Objetivos}

De acordo com as necessidades ressaltadas no item anterior, o presente trabalho objetivou avaliar a eficiência de um sistema de tratamento de esgoto sanitário, implantado em uma das unidades de uma instituição de ensino superior - Escola de Engenharia Civil da Universidade Federal de Goiás, por meio da implantação de três leitos de tratamento do tipo zona de raízes com fluxo sub-superficial horizontal, precedido de tanque séptico e reator anaeróbico, nas condições climáticas da cidade de Goiânia, GO.

\section{Metodologia}

Para a realização do estudo, foi implantado um sistema experimental de tratamento de esgoto em área da Escola de Engenharia Civil (EEC), da Universidade Federal de Goiás 
(UFG), na região leste de Goiânia-GO (latitude 1640'39' Sul e longitude 49¹4'28' Oeste). O clima local, segundo Köppen, é do tipo Aw (quente e semi-úmido com estação seca bem definida, de maio a setembro, e regime pluviométrico tropical, com temperatura média anual de $23,2^{\circ} \mathrm{C}$, com as médias mínimas e máximas de $17,9^{\circ} \mathrm{C}$ e $29,8^{\circ} \mathrm{C}$, respectivamente). A precipitação pluvial média anual é de $1.575,9 \mathrm{~mm}$ e o total anual de insolação é de $2.588,1 \mathrm{~h}$ (BRASIL, 1992).

A estação experimental utilizada neste estudo é constituída por: (1) um tanque séptico, dimensionado segundo a NBR 7.229 (ABNT, 1993); (2) um filtro anaeróbio, dimensionado segundo a NBR 13.969 (ABNT, 1997); (3) três unidades independentes de zona de raízes; (4) três reservatórios para armazenamento dos efluentes tratados. Os leitos de plantas executados podem ser classificados segundo Brix (1993) como um sistema de tratamento baseado em macrófitas emergentes de fluxo sub-superficial horizontal, dimensionada segundo orientações de Philippi et al. (2004).

O Quadro 1 apresenta as dimensões de cada uma das unidades do sistema de tratamento de esgoto utilizado para a realização deste trabalho. A Figura 1 ilustra a disposição do sistema de tratamento. A vazão média diária de esgoto aplicada no sistema de tratamento corresponde a aproximadamente $1.286 \mathrm{~L} / \mathrm{dia}$, verificada pelo método classificado por lde et al. (2010) como Método Volumétrico. Considerado um método de precisão razoavelmente boa, consiste em determinar a vazão medindo-se o tempo necessário para encher um reservatório de volume conhecido. Foi utilizado no presente estudo um reservatório de 15 Litros graduado e aferido por meio de um balão volumétrico.

Quadro 1 Dimensões das unidades do sistema experimental de tratamento de esgoto

\begin{tabular}{|c|c|c|c|c|}
\hline $\begin{array}{c}\text { Unidade do Sistema } \\
\text { de Tratamento }\end{array}$ & Diâmetro superior & Diâmetro inferior & Profundidade Útil & $\begin{array}{c}\text { Volume Útil } \\
\left(\mathrm{m}^{3}\right)\end{array}$ \\
\cline { 2 - 5 } & 2,60 & 2,00 & 2,00 & 8,00 \\
\hline Tanque séptico & 2,60 & 2,00 & 2,00 & 8,00 \\
\hline Filtro anaeróbio & 1,50 & 1,50 & 1,40 & 2,50 \\
\hline Reservatório & Largura & Comprimento & Profundidade Útil & $\begin{array}{c}\text { Volume Útil } \\
\left(\mathrm{m}^{3}\right)\end{array}$ \\
\hline $\begin{array}{c}\text { Unidade do Sistema } \\
\text { de Tratamento }\end{array}$ & 1,00 & 3,00 & 0,55 & 1,65 \\
\hline Zona de raízes & & & \\
\hline
\end{tabular}



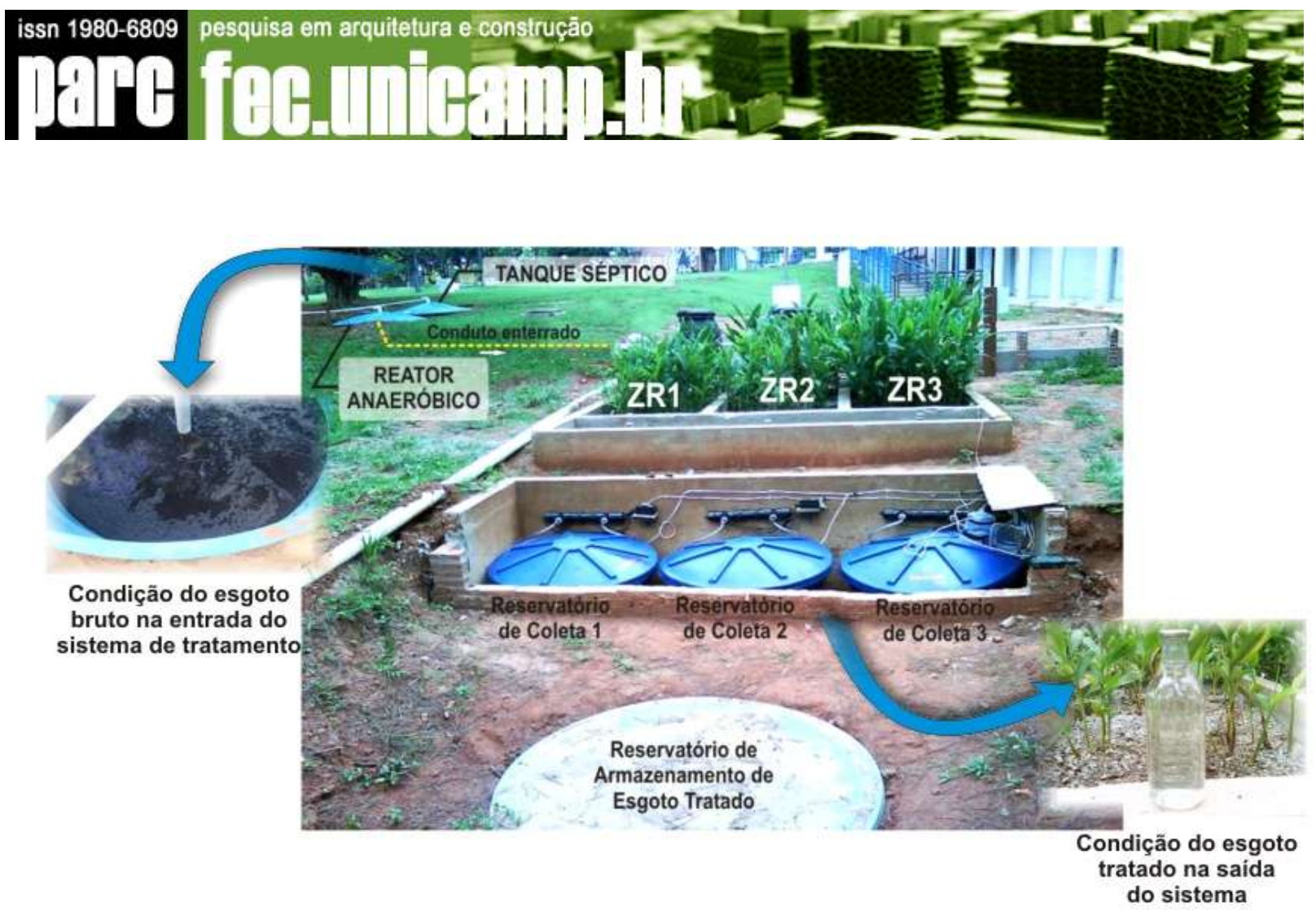

Figura 1 Estação experimental de tratamento de esgoto por plantas instalada na EEC / UFG.

O projeto foi concebido de forma a utilizar o uso do desnível disponível no terreno, possibilitando, assim o escoamento gravitacional do esgoto em maior parte das unidades do sistema de tratamento, possibilitando assim, economia de energia devido à necessidade de instalação de unidades de bombeamento. Todo esgoto gerado dentro da unidade universitária (banheiros, copa dos funcionários, cantina e laboratórios) é conduzido inicialmente a um tanque séptico, sem qualquer separação. Na seqüência o efluente é encaminhado a um filtro anaeróbio, preenchido com pedaços de manta de poliéster cortadas nas dimensões de $2,5 \times 2,5 \mathrm{~cm}$. Esta manta serve de meio suporte para as bactérias anaeróbicas que possibilitam o funcionamento desta unidade de filtração. Em seguida, o efluente é escoado para três bombonas, onde é distribuído uniformemente até atingir seu nível máximo de armazenamento. Com o objetivo de se ampliar a vazão de aplicação de esgoto nas zonas de raízes, foram instaladas em cada bombona uma bomba submersa de baixo consumo de energia, com flexibilidade para regulagem de vazão entre $60 \mathrm{~L} / \mathrm{h}$ e $170 \mathrm{~L} / \mathrm{h}$. Assim, com o propósito de regularizar a vazão de aplicação de esgoto em 180 L/dia em cada unidade de zona de raízes, as bombas foram igualmente reguladas da seguinte forma: utilizando a vazão da bomba de $60 \mathrm{~L} / \mathrm{h}$ e com ajuda de um temporizador (timer), aplica-se o 
esgoto durante 15 minutos correntes. O procedimento é retomado de duas em duas horas durante as 24 horas do dia, de segunda-feira a sábado. As aplicações são suspensas às 18h00min do sábado e/ou nas vésperas de feriados, tendo em vista que não há produção de esgoto na unidade universitária nos domingos e feriados.

O tanque séptico, o filtro anaeróbio e o reservatório são constituídos por unidades prémoldadas em fibra de vidro. Os leitos da zona de raízes foram construídas com piso em concreto armado e paredes em alvenaria de tijolo comum $(9 \mathrm{~cm} \times 19 \mathrm{~cm} \times 4 \mathrm{~cm}$, deitado), impermeabilizadas durante e após o reboco. Seus leitos foram preenchidos com brita número um nos cinquenta centímetros iniciais e finais, para facilitar a aplicação e drenagem.

A parte intermediária foi preenchida com diferentes substratos, sendo areia média lavada na zona de raízes 1 (ZR-1), brita número zero na zona de raízes 2 (ZR-2) e brita número um na zona de raízes 3 (ZR-3). A areia média lavada utilizada possui 40\% de espaços vazios, já a brita número zero e a brita numero um ambas possuem $50 \%$ de espaços vazios. A distribuição granulométrica de cada substrato pode ser vista no gráfico do ensaio granulométrico da Figura 2. Por ocasião do preenchimento do leito com substratos com diferentes granulometrias, utilizou-se tábuas de madeira para separar a brita da areia no leito 1 (ZR-1), e a brita zero da brita um no leito 2 (ZR-2), retirando-as em seguida, conforme mostra a Figura 3.

As três unidades foram vegetadas com a espécie lírio-do-brejo (Hedychium coronarium J. König). A espécie vegetal foi escolhida por proporcionar um efeito paisagístico, dispersão de aromas e alta eficiência no tratamento de esgoto sanitário nas condições climáticas de Goiânia - GO (ALMEIDA et al., 2007; ALMEIDA, 2005). No transplante das espécies vegetais foram utilizadas mudas correspondentes a plantas adultas com brotações no rizoma, na densidade de oito plantas por metro quadrado. As plantas foram previamente coletadas em seu ambiente natural, tiveram suas folhas cortadas e foram armazenadas em local úmido e sombreado, com vistas à brotação. Após o transplantio das mudas procedeu-se a sua irrigação com água de torneira (do sistema público). As plantas que morreram foram substituídas, de forma a manter o estande de plantas. Seguindo as recomendações de Sievers (1993) e Solano et al. (2004), após o início de desenvolvimento das plantas (o que ocorreu trinta dias após o transplante), iniciou-se a aplicação do esgoto. 

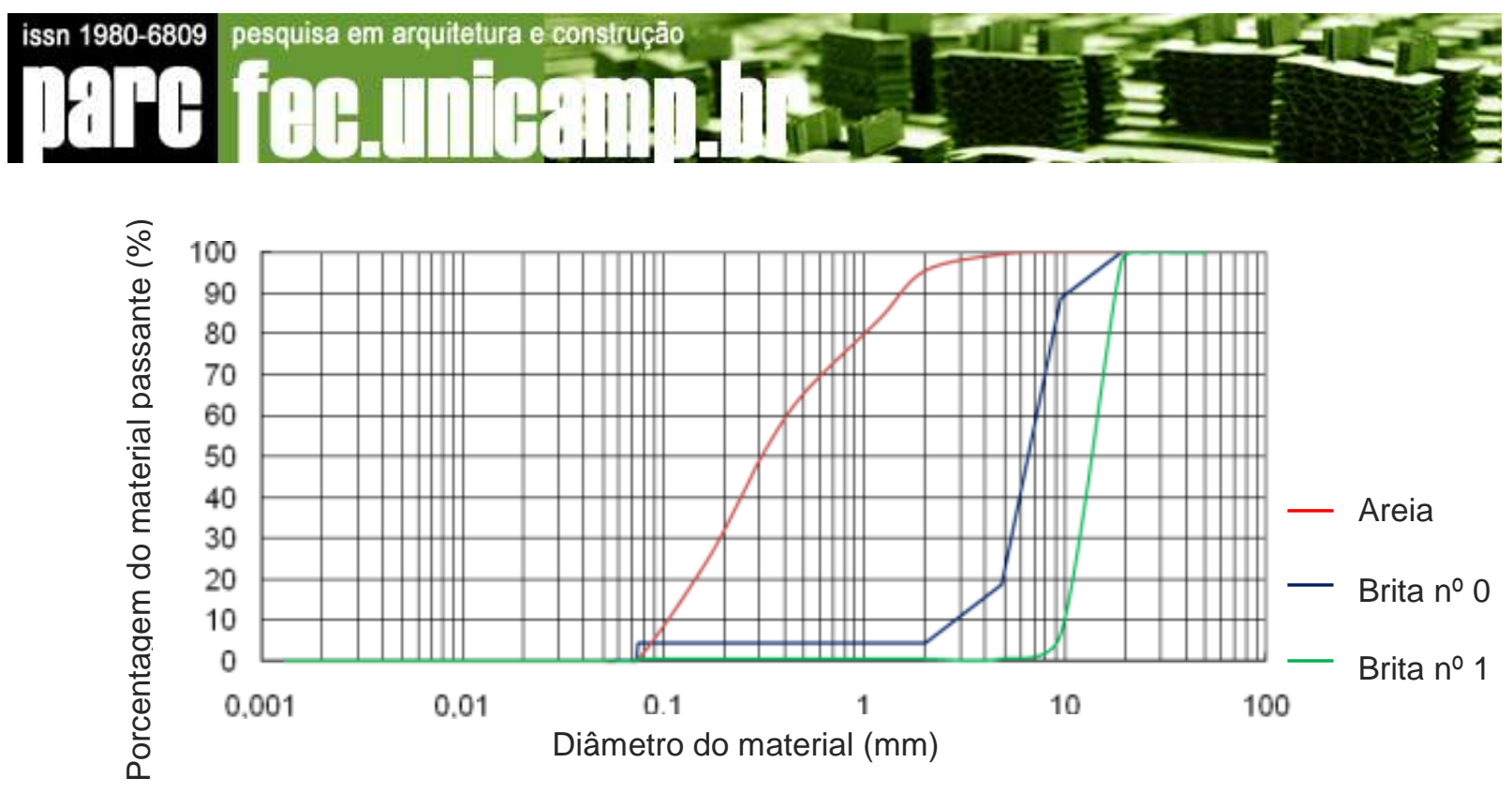

Figura 2 Ensaio Granulométrico dos substratos utilizados no preenchimento dos leitos das zonas de raízes

Em uma das extremidades do leito das zonas de raízes, foi instalado um tubo de esgoto de $100 \mathrm{~mm}$ de diâmetro, perfurado, posicionado no terço superior da altura útil da unidade. Esse tubo recebe a aplicação de esgoto por meio das bombas submersas instaladas nas bombonas e, distribui uniformemente o esgoto na zona de raízes. A drenagem do efluente dá-se pela extremidade oposta à entrada, por meio de um tubo de esgoto de $50 \mathrm{~mm}$ de diâmetro, também perfurado, posicionado no fundo do leito, conforme ilustra a Figura 3.

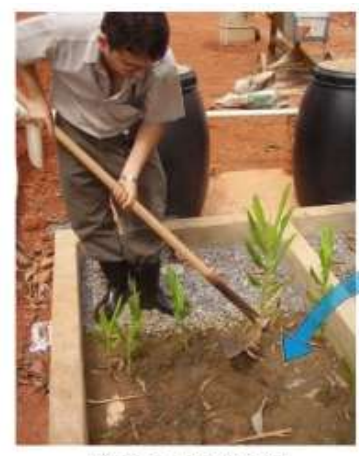

Etapa de plantio das mudas de lírio do brejo no leito 1
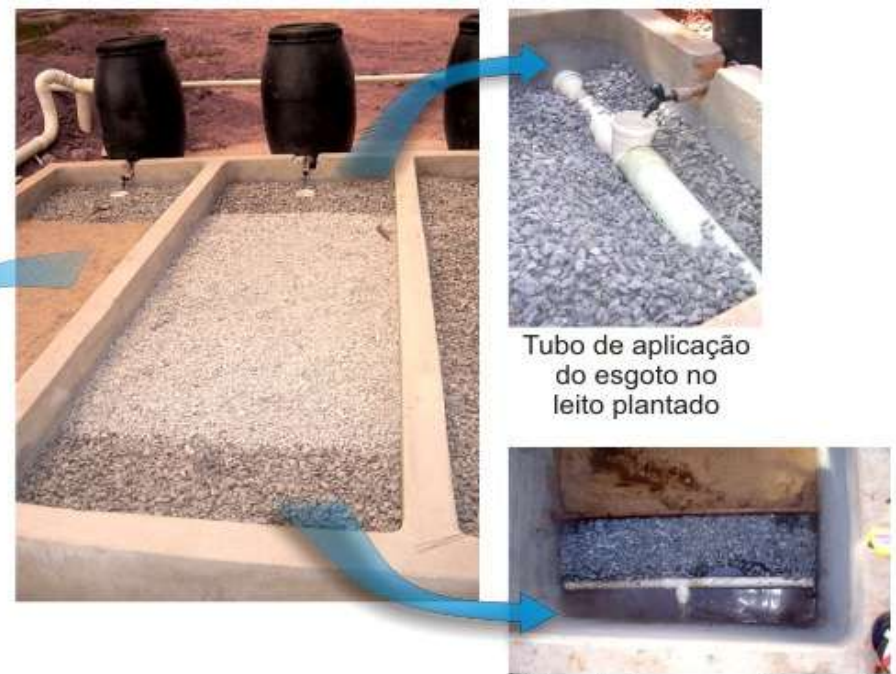

Tubo de drenagem do esgoto tratado no fundo do leito plantado

Figura 3 Detalhe executivo do tubo de aplicação de esgoto, do dreno de esgoto tratado e da etapa de plantio dos leitos das zonas de raízes 
Para manter o nível a aproximadamente cinco centímetros abaixo da superfície do substrato, com vistas a evitar seu afloramento e a conseqüente proliferação de mosquitos e liberação de mau cheiro, foram acoplados na tubulação de drenagem de cada unidade um joelho com $90^{\circ}$ e diâmetro de $50 \mathrm{~mm}$, juntamente com um tubo na vertical de $60 \mathrm{~cm}$, cujo posicionamento determina a altura máxima do nível do líquido dentro das zonas de raízes. Após passar pelo leito plantado (zonas de raízes) o esgoto é encaminhado para um reservatório de armazenamento. Caso o efluente tratado não seja utilizado, ele é encaminhado através de um extravasor à caixa de ligação de esgoto da EEC / UFG e, posteriormente é encaminhado para o coletor da rede pública de esgoto.

Após um mês do início da aplicação de esgoto, foram coletadas amostras quinzenais do efluente por um período de seis meses, para a realização de análises de qualidade da água e determinação da eficiência do sistema de tratamento. Anteriormente ao início das coletas, foram coletadas amostras compostas do esgoto bruto, para fins de caracterização do mesmo, e amostras simples na saída do tanque séptico, na saída do filtro anaeróbio e após cada unidade de zonas de raízes. Foram avaliados a Demanda Bioquímica de Oxigênio (D.B.O.), Demanda Química de Oxigênio (D.Q.O.), Coliformes Termotolerantes, dentre outras.

\section{Resultados e Discussão}

O dimensionamento do tanque séptico e do filtro anaeróbio do sistema de tratamento foi calculado com base no levantamento da quantidade de pessoas que permanecem na unidade durante o expediente. Entretanto, após a instalação das unidades, verificou-se que a vazão média de esgoto correspondia a aproximadamente 1.286 L/dia. De posse desta nova vazão, observou-se um superdimensionamento do tanque séptico e do filtro anaeróbio, uma vez que o tempo de detenção real ficou bem acima do sugerido pela NBR 7.229 (ABNT, 1993).

O tempo de detenção hidráulica (TDH) do esgoto foi de 6,2 dias no tanque séptico e 6,2 dias no filtro anaeróbio. Para as unidades de zona de raízes, que permitem controle da vazão de entrada por meio do ajuste das bombas, foram fixadas vazões de $180 \mathrm{~L} /$ dia, o que gerou tempos de detenção, considerando o material de preenchimento, na ordem de 4 dias para ZR-1 e 4,6 dias para ZR-2 e ZR-3, totalizando 16,4 dias no sistema de tratamento com a ZR1 e 17 dias no sistema de tratamento com ZR-2 e ZR3, conforme mostra o Quadro 2. 
Quadro 2 Dimensões, Volume Útil e Tempo de Detenção Hidráulica propiciados pelas unidades do sistema

\begin{tabular}{|c|c|c|c|c|c|c|c|}
\hline $\begin{array}{c}\text { Unidade do } \\
\begin{array}{c}\text { Sistema de } \\
\text { Tratamento }\end{array}\end{array}$ & $\begin{array}{c}\text { Diâmetro } \\
\text { superior }\end{array}$ & $\begin{array}{c}\text { Diâmetro } \\
\text { inferior }\end{array}$ & $\begin{array}{c}\text { Profundidade } \\
\text { Útil }\end{array}$ & $\begin{array}{c}\text { Volume } \\
\text { Útil }\left(\mathrm{m}^{3}\right)\end{array}$ & $\begin{array}{c}\text { Vazão } \\
(\text { L/dia) }\end{array}$ & $\begin{array}{c}\text { Espaços de } \\
\text { vazios (\%) }\end{array}$ & $\begin{array}{c}\text { TDH } \\
\text { (dias) }\end{array}$ \\
\hline Tanque séptico & 2,60 & 2,00 & 2,00 & 8,00 & 1.286 & - & 6,2 \\
\hline Filtro anaeróbio & 2,60 & 2,00 & 2,00 & 8,00 & 1.286 & - & 6,2 \\
\hline Reservatório & 1,50 & 1,50 & 1,40 & 2,50 & 180 & - & 13,8 \\
\hline $\begin{array}{c}\text { Unidade do } \\
\text { Sistema de } \\
\text { Tratamento }\end{array}$ & Largura & Comprimento & $\begin{array}{c}\text { Profundidade } \\
\text { Útil }\end{array}$ & $\begin{array}{c}\text { Volume } \\
\text { Útil }\left(\mathrm{m}^{3}\right)\end{array}$ & $\begin{array}{c}\text { Vazão } \\
\text { (L/dia) }\end{array}$ & $\begin{array}{c}\text { Espaços de } \\
\text { vazios (\%) }\end{array}$ & $\begin{array}{c}\text { TDH } \\
\text { (dias) }\end{array}$ \\
\hline ZR-1 & 1,00 & 3,00 & 0,55 & 1,65 & 180 & $40 \%$ & 4 \\
\hline ZR-2 & 1,00 & 3,00 & 0,55 & 1,65 & 180 & $50 \%$ & 4,6 \\
\hline ZR-3 & 1,00 & 3,00 & 0,55 & 1,65 & 180 & $50 \%$ & 4,6 \\
\hline
\end{tabular}

Quanto à avaliação de eficiência das unidades do sistema de tratamento, pode-se afirmar que por meio da média das amostras coletadas a eficiência do tanque séptico na purificação do esgoto foi de $71 \%$ nos níveis de DBO, de 69,6\% nos níveis de DQO e de 93,31\% na contagem de coliformes termotolerantes. Já o filtro biológico anaeróbico promoveu uma redução de 35,6\% nos níveis de DBO, de 31,7\% nos níveis de DQO e de 82,02\% na contagem de coliformes termotolerantes.

No filtro biológico anaeróbico como dito anteriormente, utilizou-se como meio suporte para formação de biofilme a manta de poliéster cortada em pedaços de $25 \mathrm{~mm}$. Optou-se pela manta de poliéster por ser um material bem menos pesado e ter o custo compatível com os demais meios suportes, a exemplo da brita. Além disto, a constituição do material oferece boa aderência para os microrganismos e proporciona uma grande área de superfície de contato. Porém, é importante ressaltar que o material foi colocado gradativamente na unidade de filtração durante o período da pesquisa, quando o ideal seria colocar de uma única vez no início do processo. Esse imprevisto pode ser um dos motivos da baixa eficiência da unidade, uma vez que a literatura apresenta uma eficiência global de remoção da DBO de 75\% a 85\%, em relação ao efluente do tanque séptico (JORDÃO et al., 2005).

O leito da ZR-1 ocasionou redução de 92\% nos níveis de DBO, 79,7\% nos níveis de DQO e $99,2 \%$ na contagem de coliformes termotolerantes. Já o leito da ZR-2 obteve uma redução de $86,2 \%$ (DBO), 75,5\% (DQO) e 98,4\% (coliformes termotolerantes). O leito da ZR-3 promoveu 
uma redução de $87,4 \%$ de DBO, $71,9 \%$ de DQO e $97,6 \%$ para os coliformes termotolerantes, conforme mostra a Tabela 1.

A eficiência global na redução da DBO foi de $98,5 \%$ com o sistema ZR-1, resultando num efluente com $7 \mathrm{mg} \mathrm{O}_{2} \mathrm{~L}^{-1}, 97,4 \%$ com o sistema ZR-2, resultando num efluente com $12 \mathrm{mg} \mathrm{O} 2$ $\mathrm{L}^{-1}$ e $97,6 \%$ com o sistema ZR-3, resultando num efluente com $11 \mathrm{mg} \mathrm{O}_{2} \mathrm{~L}^{-1}$. A legislação estabelece uma DBO máxima de $60 \mathrm{mg} \mathrm{O}_{2} \mathrm{~L}^{-1}$ para o efluente das estações de tratamento de esgoto ou uma redução mínima de $80 \%$ na concentração de DBO. Para o lançamento em corpos receptores de água doce de Classe 2, o efluente não pode elevar a concentração de DBO acima de $5 \mathrm{mg} \mathrm{O}_{2} \mathrm{~L}^{-1}$. Tampouco, pode resultar na redução da concentração de OD abaixo de $5 \mathrm{mg} \mathrm{O}_{2} \mathrm{~L}^{-1}$. Todos os substratos atenderam à legislação vigente.

Tabela 1 Eficiência de tratamento de cada unidade do sistema estudado.

\begin{tabular}{|c|c|c|c|}
\hline Unidades & $\begin{array}{c}\mathrm{DBO}^{1} \\
\left(\mathrm{mg} \mathrm{O}_{2} / \mathrm{L}\right)\end{array}$ & $\begin{array}{c}\mathrm{DQO}^{2} \\
\left(\mathrm{mg} \mathrm{O}_{2} / \mathrm{L}\right)\end{array}$ & $\begin{array}{c}\text { CT }^{3} \\
\text { (N.M.P./100mL) }\end{array}$ \\
\hline Esgoto bruto & 465 & 1113 & $5,7.10^{\prime}$ \\
\hline Após tanque séptico & 135 & 338 & $3,8.10^{6}$ \\
\hline Redução (\%) & 71 & 69,6 & 93,31 \\
\hline Após filtro anaeróbio & 87 & 231 & $6,8.10^{5}$ \\
\hline Redução (\%) & 35,6 & 31,7 & 82,02 \\
\hline Redução Total (\%) & 81,3 & 79,2 & 98,80 \\
\hline Após ZR-1 ${ }^{4}$ & 7 & 47 & $5,6.10^{3}$ \\
\hline Redução (\%) & 92 & 79,7 & 99,18 \\
\hline Redução Total (\%) & 98,5 & 95,8 & 99,99 \\
\hline Após ZR-2 ${ }^{5}$ & 12 & 59 & $1,1.10^{4}$ \\
\hline Redução (\%) & 86,2 & 74,5 & 98,36 \\
\hline Redução Total (\%) & 97,4 & 94,7 & 99,98 \\
\hline Após ZR-3 ${ }^{6}$ & 11 & 65 & $1,6.10^{4}$ \\
\hline Redução (\%) & 87,4 & 71,9 & 97,6 \\
\hline Redução Total (\%) & 97,6 & 94,2 & 99,97 \\
\hline
\end{tabular}


Solano et al. (2004), na Espanha, observaram uma eficiência da taboa na redução da DBO de 81\%, para aplicação de 75 litros diários de esgoto por metro quadrado, no verão. Gersberg et al. (1986), na Califórnia, verificaram eficiência de 74\%. Van Kaick (2002), no Paraná, observou redução de 83,9\%. Costa et al. (2003), na Paraíba, constataram redução de 88\%. Presznhuk et al. (2003), no Paraná, observaram redução de 84,2\%. Em Goiás, Pitaluga et al. (2009) constataram eficiência de 90,7\% na redução de DBO.

A eficiência global na redução da DQO foi de 95,8\% com o sistema ZR-1, resultando num efluente com $47 \mathrm{mg} \mathrm{O}_{2} \mathrm{~L}^{-1}, 94,7 \%$ com o sistema ZR-2, resultando num efluente com $59 \mathrm{mg}$ $\mathrm{O}_{2} \mathrm{~L}^{-1}$ e $94,2 \%$ com o sistema ZR-3, resultando num efluente com $65 \mathrm{mg} \mathrm{O}_{2} \mathrm{~L}^{-1}$. Em Goiás, Pitaluga et al. (2009) constataram eficiência de $81 \%$ na redução de DQO, valor próximo à média das eficiências verificadas por Solano et al. (2004), Gersberg et al. (1986), Van Kaick (2002), Presznhuk et al. (2003). Assim, a eficiência verificada neste trabalho foi bastante satisfatória, superior ao observado em sistemas das mais variadas concepções e em várias regiões do mundo.

A remoção de coliformes termotolerantes foi de quatro casas exponenciais na ZR-1 e três casas exponenciais nas ZR-2 e ZR-3, resultando em uma concentração de 5.609, 11.238 e 16.263 NMP $100 \mathrm{~mL}^{-1}$, respectivamente. A legislação brasileira não determina limite de coliformes para os efluentes de estações de tratamento de esgoto. Todavia, a contribuição do efluente não pode elevar a contagem de coliformes termotolerantes nos corpos receptores acima dos limites estabelecidos para cada classe; ou seja, $1.000 \mathrm{NMP} 100 \mathrm{~mL}^{-1}$, para os de Classe 2 (CONAMA, 2005). Verifica-se, portanto, que o efluente deve sofrer um polimento final (desinfecção) antes de ser disposto em mananciais hídricos de pequena vazão, sob risco de propiciar a elevação da contagem de coliformes acima do permitido.

Embora este estudo tenha sido desenvolvido no tratamento de esgotos de uma unidade de ensino superior, vislumbra-se a possibilidade de se extrapolar os resultados para sua utilização em pequenas comunidades urbanas, de igual porte.

\section{Conclusões}

Os resultados observados permitem concluir que o sistema de tratamento do tipo zona de raízes precedida por tanque séptico e filtro anaeróbio é eficiente na purificação do esgoto sanitário nas condições climáticas da região de Goiânia, atendendo ao estabelecido na 
legislação vigente (CONAMA, 2005) para a Demanda Química de Oxigênio, a Demanda Bioquímica de Oxigênio e os Coliformes Termotolerantes.

\section{Agradecimentos}

Os autores agradecem à Agência Nacional de Águas - ANA, à Saneamento de Goiás S/A Saneago, à Secretaria das Cidades, à Universidade Federal de Goiás - UFG e à Eternit S/A, pelo apoio recebido.

\section{Referências}

ABNT - ASSOCIAÇÃO BRASILEIRA DE NORMAS TÉCNICAS 1993, NBR 7229: projeto, construção e operação de sistemas de tanques sépticos: procedimento. Rio de Janeiro. ABNT - ASSOCIAÇÃO BRASILEIRA DE NORMAS TÉCNICAS 1997, NBR 13969: tanques sépticos: unidades de tratamento complementar e disposição final dos efluentes líquidos: projeto, construção e operação. Rio de Janeiro, 1997.

ALMEIDA, R. A. 2005, Substratos e plantas no tratamento de esgoto por zona de raízes. Tese (Doutorado em Agronomia: Produção Vegetal)-Escola de Agronomia e Engenharia de Alimentos, Universidade Federal de Goiás, Goiânia, 108 p.

ALMEIDA, R. A.; OLIVEIRA, L. F. C.; KLIEMANN, H. J. 2007, Eficiência de espécies vegetais na purificação de esgoto sanitário. Pesquisa Agropecuária Tropical, Goiânia, v. 37, n. 1, p. $1-9$.

BRASIL. 1992, Ministério da Agricultura e Reforma Agrária. Secretaria Nacional de Irrigação. Departamento Nacional de Meteorologia. Normais climatológicas: 1961-1990. Brasília, DF, 84 p.

BRIX, H. 1993, Wastewater treatment in constructed wetlands: system design, removal processes, and treatment performance. In: MOSHIRI, G.A. (Ed.) Constructed wetlands for water quality improvement. Boca Raton: CRC Press, p. 9-23.

CONAMA (Brasil) 2005, Resolução nº 357. Dispõe sobre a classificação dos corpos de água e diretrizes ambientais para o seu enquadramento. D.O.U. Brasília, DF, ano 142, n. 53, seção 1, p. 58-63.

COSTA, L. L. et al. 2003, Eficiência de wetlands construídos com dez dias de detenção hidráulica na remoção de colífagos e bacteriófagos. Revista de Biologia e Ciências da Terra, Belo Horizonte, v. 3, n. 1, p.1-23. 
GERSBERG, R. M. et al. 1986, Role of aquatic plants in wastewater treatment by artificial wetlands. Water Research, Hallioxford, v. 20, n. 3, p. 363-368.

HELLER, L.; NASCIMENTO, N. O. 2005, Pesquisa e desenvolvimento na área de saneamento no Brasil: necessidades e tendências. Engenharia Sanitária e Ambiental, Rio de Janeiro, v. 10, n. 1, p. 24-35.

IDE, C. N.; OLIVEIRA, K. R. F.; BEZERRA, L. P. 2010, Sistema de Esgotamento Sanitário Coleta de amostras de água e esgoto: Guia do profissional em treinamento - Recesa <http://vsites.unb.br/ft/enc/recursoshidricos/NURECO/arq/CAEA/CAEAv2.pdf> Acesso em: 27 abril 2010.

JORDÃO, E. P.; PESSÔA, C. A. 2005, Tratamento de esgotos domésticos. 4. ed. Rio de Janeiro: ABES, $932 \mathrm{p}$.

PARESCHI, D. C. 2004, Caracterização da fauna de rotífera em área alagada construída para tratamento de esgoto doméstico - Piracicaba (SP). Originalmente apresentada como dissertação de mestrado, Escola de Engenharia de São Carlos - Universidade de São Paulo, $168 \mathrm{p}$.

PARKINSON, J.N.; SIQUEIRA, E.Q.; CAMPOS, L.C. 2004, Tratamento de esgotos domésticos de pequenas comunidades utilizando áreas alagadas construídas (AACs). Revista Intercursos, v. 3, n.2, p. 135-139.

PHILIPPI, L.S.; SEZERINO, P.H. 2004, Aplicação de sistemas tipo wetlands no tratamento de águas residuárias: utilização de filtros plantados com macrófitas. Florianópolis, Ed. do autor, 144 p.

PITALUGA, D. P. S.; ALMEIDA, R. A.; REIS, R. P. A.; MARTINS, L. L. 2009, Tratamento de esgoto doméstico por zona de raízes precedida de tanque séptico: eficiência do sistema e potencial de reúso do efluente. 25ํㅡㄹ Congresso brasileiro de engenharia sanitária e ambiental, 2009, Recife. Anais... Recife: ABES, II-100, CD-ROM.

PRESZNHUK, R. A. O. et al. 2003, Tecnologia apropriada e saneamento: análise de eficiência de estações de tratamento de esgoto por meio de zona de raízes. In: SEMANA DE TECNOLOGIA: TECNOLOGIA PARA QUEM E PARA QUÊ? Um Olhar Interdisciplinar, 2003, Curitiba. Anais... Curitiba: Cefet-PR, p. 336-340.

SIEVERS, D. M. 1993, Design of submerged flow wetlands for individual homes and small wastewater flows. Columbia: University of Missouri. 11 p. (Special Report, 457). 


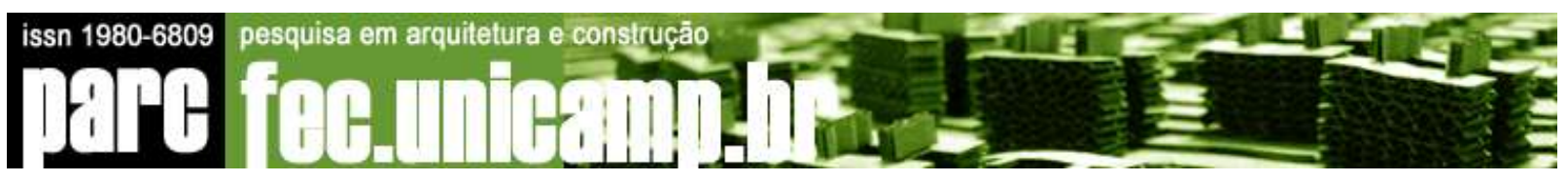

SOLANO, M.L.; SORIANO, P.; CIRIA, M.P. 2004, Constructed wetlands as a sustainable solution for wastewater treatment in small villages. Biosystems Engineering, London, v. 87, n. 1, p. 109-118.

VALENTIM, M.A.A. 2003, Desempenho de leitos cultivados ("constructed wetland") para tratamento de esgoto: contribuições para concepção e operação. Tese (Doutorado em Engenharia Agrícola: Água e Solo)-Faculdade de Engenharia Agrícola, Universidade Estadual de Campinas, Campinas, SP, $233 \mathrm{p}$.

VAN KAICK, T.S. 2002, Estação de tratamento de esgoto por meio de zona de raízes: uma proposta de tecnologia apropriada para saneamento básico no litoral do Paraná. Dissertação (Mestrado) - Centro Federal de Educação Tecnológica do Paraná, Curitiba. 116 p. 